\title{
The ocean's new frontier
}

Last update: 14 March 2017

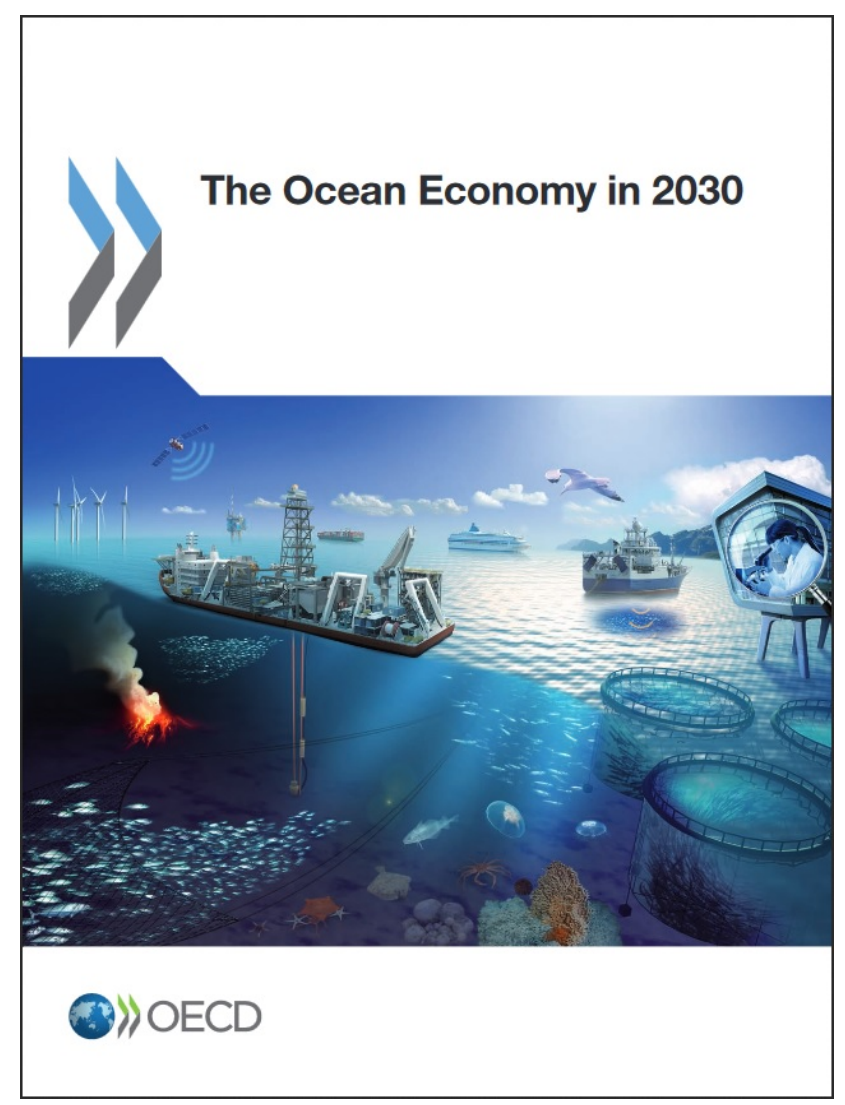

Oceans hold the promise of immense resource wealth and great potential for boosting economic growth, employment and innovation. In the same time, they are recognised as indispensable for addressing many of the global challenges facing the planet, from food security and climate change to the provision of energy, natural resources and health care. But they are already over-exploited, polluted and confronted with climate change.

The ocean economy encompasses industries such as shipping, fishing, offshore wind and marine biotechnology. It is also a natural asset and ecosystem, whether for fish, shipping lanes, or carbon dioxide absorption. Its global economy's contribution was valued at US $\$ 1.5$ trillion and 31 million jobs in 2010. Offshore oil and gas accounted for a third of total value added of the ocean-based industries, followed by maritime and coastal tourism, maritime equipment and ports. The largest employers were industrial capture fisheries with over a third of the total, 
and maritime and coastal tourism with almost a quarter. The projections suggest that between 2010 and 2030 on a "business-as-usual" basis, the ocean economy could more than double its contribution to global value added, reaching over US $\$ 3$ trillion, and employing some 40 million people in 2030.

While this "blue economy" is expanding rapidly, oceans are under stress. As anthropogenic carbon emissions have risen over time, the ocean has absorbed much of the carbon dioxide, leading to acidification. Also, sea temperatures and sea levels are rising and ocean currents (and atmospheric air flows) shifting, resulting in biodiversity and habitat loss, changes in fish stock composition and migration patterns, and higher frequency of severe weather events. The prospects for future ocean development are further aggravated by land-based pollution such as agricultural run-off, as well as by overfishing and depleted fish stocks in many parts of the world.

Realising the full potential of the ocean will therefore demand responsible, sustainable approaches to its development. A new OECD report, The Ocean Economy in 2030, puts forward four main recommendations: fostering greater international co-operation in maritime science and technology; strengthening integrated ocean management; improving the statistical and methodological base at national and international level; and building more capacity for ocean industry foresight.

See OECD video on the blue economy: http://bit.ly/1Nkwkpq

\section{References}

The Ocean Economy in 2030 http://dx.doi.org/10.1787/9789264251724-en

Crawford Heitzmann, Martha (2006), “Don't forget the coastal waters!”, OECD Observer No 254, March http://oecdobserver.org/news/fullstory.php/aid/ 1807/Don_92t_forget_the_coastal_waters!.html 